\title{
ESCUTAR COM O CORPO INTEIRO: O EXERCÍCIO DE ABERTURA ATENCIONAL COMO EXPERIÊNCIA SENSÍVEL NOS PROCESSOS DE APRENDIZAGEM
}

Cristiane Bremenkamp Cruz ${ }^{\mathrm{i}}$ Maria Elizabeth Barros de Barros ${ }^{\text {ii }}$

\begin{abstract}
Resumo: Este artigo pretende se constituir como um ensaio textual a partir do encontro com o trabalho da exímia percussionista escocesa Evelyn Glennie e alguns autores do campo da filosofia, da psicologia e da educação. Articulamos tessituras entre as noções de atender e de escutar com o corpo inteiro e buscamos fornecer pistas para uma aprendizagem da sensibilidade, da atenção e da escuta. Apontamos a experiência de cultivo de uma disponibilidade do corpo entendido como "caixa de ressonâncias", concluindo que mais do que linhas visíveis, regras, disciplinas e métodos rígidos de comportamento, o que ganha destaque nessa aposta ética de uma aprendizagem da sensibilidade é o que, no invisível, sustenta o encontro e a atmosfera crucial dos processos de ensino-aprendizagem: um pouco de abertura e de frescor.
\end{abstract}

Palavras-chave: Aprendizagem da atenção; Experiência corporificada; Escuta.

\section{ESCUCHAR CON TODO EL CUERPO: EL EJERCICIO DE APERTURA ATENCIONAL COMO EXPERIENCIA SENSIBLE EN LOS PROCESOS DE APRENDIZAJE}

Resumen: Este artículo pretende ser un ensayo textual basado en un encuentro con el trabajo de la percusionista escocesa Evelyn Glennie y algunos autores del campo de la filosofía, la psicología y la educación. Articulamos las lecturas entre las nociones de cuidado y escucha con todo el cuerpo y buscamos proporcionar pistas para una aprendizaje da sensibilidad, atención y escucha. Señalamos la experiencia de cultivar una disponibilidad del cuerpo entendido como una "caja de resonancia", concluyendo que más que líneas visibles, reglas, disciplinas y métodos rígidos de comportamiento, lo que se destaca en esta apuesta ética de un aprendizaje de la sensibilidad es que, en lo invisible, sostiene el encuentro y la atmósfera crucial de los procesos de enseñanza-aprendizaje: un poco de apertura y frescura.

Palabras clave: Aprendizaje de atención; Experiencia encarnada; Escucha.

\section{Introdução}

Este artigo pretende se constituir como um ensaio textual a partir do encontro com o trabalho da exímia percussionista escocesa Evelyn Glennie e alguns autores do campo da filosofia, da psicologia e da educação. Articulamos tessituras entre as noções de atender (no

2019 Bremenkamp Cruz; Barros de Barros. Este é um artigo de acesso aberto distribuído sob os termos da Licença Creative Commons Atribuição Não Comercial-Compartilha Igual (CC BY-NC-4.0), que permite uso, distribuição e reprodução para fins não comercias, com a citação dos autores e da fonte original e sob a mesma licença. 


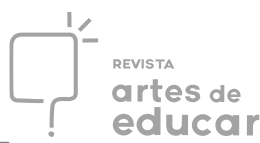

sentido de atentar-se) e de escutar com o corpo inteiro com base em ideias contidas no documentário intitulado Touch the sound, no qual Evelyn Glennie afirma que escutar é uma forma especializada de "toque". Neste documentário, a musicista menciona ainda que nós poderemos experimentar colorações sonoras singulares em distintos espaços que povoam uma sala de aula, por exemplo, como em um caleidoscópio auditivo no qual se convida à sinestesia corporal e à experimentação sensível com o espaço habitado.

No ensaio intitulado "Hearing essay", escrito em 2015, Evelyn Glennie desmancha o que considera um mal-entendido a respeito do exercício de ouvir. A percussionista considera que escutar diz respeito basicamente a uma "forma especializada de toque" e que o som é um ar vibrante captado pelo ouvido, que se converte em sinais elétricos para serem interpretados. Desse modo, o senso de audição, assim como o toque, cumpre uma função comum.

Se você está de pé na estrada e um grande caminhão passa, você ouve ou sente a vibração? A resposta é ambas. Com vibrações de frequência muito baixa, o ouvido começa a se tornar ineficiente e o restante do tato do corpo passa a assumir o controle. Por alguma razão, tendemos a fazer uma distinção entre ouvir um som e sentir uma vibração, mas na realidade são a mesma coisa [...] Surdez não significa que você não pode ouvir, apenas que há algo errado com os ouvidos. Mesmo alguém que é totalmente surdo ainda pode ouvir/sentir sons (GLENNIE, 2015).

Desmanchar esse mal-entendido é notadamente frequente no cotidiano de Evelyn Glennie, pois ela se tornou uma exímia percussionista solo mesmo sendo acometida por uma deficiência auditiva grave que a acompanha desde criança. Em virtude de tal singularidade, entrevistadores e o público em geral frequentemente a questionam sobre a sua potência de ouvir. Em resposta às reiteradas perguntas sobre esse tema, a musicista nos convida a desfazer uma noção reduzida de surdez como bloco homogêneo habitado por um mundo de completo silêncio.

Glennie afirma que escutamos com o corpo inteiro e que nossos corpos funcionam como uma "caixa de ressonâncias". À pergunta endereçada a ela "Se todos podemos sentir vibrações de baixa frequência, por que não podemos sentir vibrações mais elevadas?", Glennie responde que nós podemos, certamente, sentir vibrações mais elevadas, porém à medida que a frequência aumenta, nossos ouvidos se tornam mais eficientes e abafam a sensação sutil de "sentir" as vibrações que acompanham os sons.

A percussionista conta ainda que, durante sua juventude, despendia horas com as mãos contra as paredes da sala de aula onde estudava, enquanto seu professor de percussão tocava Revista Interinstitucional Artes de Educar. Rio de Janeiro, V. 5, N.3- pág. 439-453 set-dez de 2019: “Educação: Corpo em movimento." - DOI: 10.12957/riae.2019.45776 


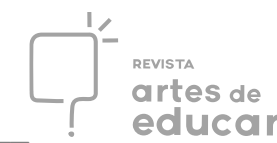

notas distintas ajudando-a a refinar sua audição corporal e detectar as vibrações do ambiente. Além da audição de sons e da sensação corporal das vibrações, Evelyn Glennie inclui na participação da experiência auditiva o papel da visão, complexificando a prática da escuta que sinestesia completamente a experiência corporal.

A musicista afirma, por exemplo, que quando vemos uma folha de árvore se mover ao vento, mesmo sem perceber, acabamos por gerar um som para ela, e ainda incutimos esse gesto sonoro em quaisquer outros objetos que caiam no chão, por exemplo. Quando um entrevistador lhe pergunta “Como você ouve o que está tocando?", Glennie responde pacientemente que ela ouve como todas as pessoas ditas normais ouvem, isto é: a percussionista nos convida a fazer contato com a experiência mais ampla do corpo como uma caixa de ressonâncias, convocandonos a perceber dimensões sutis da experiência que na correria e no automatismo cotidianamente deixamos de notar com densidade e distinção.

Poderíamos dizer, sintonizados com o trabalho de Evelyn Glennie, que para escutar é indicado que adotemos uma postura de "leitores de hieróglifos", dispostos a penetrar texturas, como dizia o filósofo Gilles Deleuze (1987). Devemos nos abrir de modo ao mesmo tempo sensível, prudente, aberto e experimentador. Em outras palavras, na perspectiva compartilhada por Deleuze e Glennie, escutar é um gesto que diz respeito a entrar em contato com paisagens melódicas, atmosferas e vibratilidades subjacentes ao que se diz/escuta.

Claire Petitmengin (2007) menciona essa qualidade relacional ao dizer que, a fim de contar uma história para seus ouvintes, é essencial que um bom contador redescubra em si o universo de sentido que pretende transmitir, isto é, que ausculte os marcos formadores, além das articulações da história e do sentido intuído que o guia.

Petitmengin (2007) também afirma que entrar em contato com essa dimensão não verbal da experiência é particularmente bem demonstrado em processos de tradução. A autora ressalta que, longe de fazer uma operação de transcodificação entre duas línguas (consistindo em encontrar as estruturas gramaticais correspondentes no intervalo entre elas), um bom tradutor não simplesmente traduz palavras, mas "faz um desvio" através do sentido não verbal subjacente a elas. Deleuze também afirmava esse imperativo de modo poético: há apenas palavras inexatas para designar alguma coisa exatamente (DELEUZE; PARNET, 1998, p. 4).

O professor budista Lama Padma Samten fala frequentemente em "aprendizado pelas costas"1 para se referir a esse modo de ensinar e aprender que se transmite por gestos silenciosos e posturas inauditas, mais do que por palavras, sentenças e discursos. Lama Padma Samten 


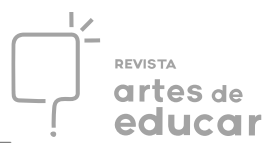

parece se referir a um aspecto de mudança de atmosfera produzida quando tal qualidade de vínculo se instaura.

Nessa direção, o monge vietnamita Thich Nhat Hanh (1996), em reflexões acerca da relação entre adultos e crianças na produção de vínculos constitutivos, também afirma algo similar. Ele conta que gostava muito de ler histórias para as crianças vietnamitas refugiadas de quem ele ajudava a cuidar. O monge ressalta sua consideração de que as crianças gostavam de ficar ao seu redor, não pelas histórias em si que ele lia, tampouco pelas balas e outros doces que eventualmente ele distribuía aos pequenos. Afirma que as crianças gostam de estar com os adultos, compartilhar sua presença e desfrutar desse encontro. E embora nos portemos de modo a sempre achar que precisamos elogiá-las, presenteá-las e premiá-las, esta não é a linha de maior força na constituição de vínculo e conexão.

Para Thich Nhat Hanh (1996), o que realmente atrai as crianças é poder "ouvir" o frescor da convivência tecida em companhia. As crianças - assim como os estudantes próximos de um professor - percebem quando há inteireza e disponibilidade sustentadas na relação, quando há uma presença que as ouve com o corpo inteiro, isto é, quando nos permitimos ser interpelados por elas em vez de simplesmente interditá-las ou subjugá-las.

Vale ressaltar que o sentido de "frescor" aqui nada tem a ver com a brevidade da constituição de um vínculo; diz respeito antes a um modo de presença e disponibilidade, de coordenação e abertura. Em outras palavras, trata-se de uma qualidade de produção de vínculo que é também um modo de conexão. Quando uma pessoa corporifica tal disposição ética para a ação, isto é, quando alguém sussurra um vento "escutadeiro", franco e sutil em nossas costas, certamente atrairá a presença e a disponibilidade de quem o rodeia. Respirar o estado de presença e a pacificação instaurada nessas condições é, sem dúvida, profundamente restaurador, convidativo e vinculador.

Em outras palavras, podemos dizer que a experiência de cultivar uma disponibilidade sensível parece-nos passar pelo acolhimento dessa atmosfera de abertura do corpo entendido como “caixa de ressonâncias”. Mais do que linhas visíveis, regras, disciplinas e métodos rígidos de comportamento, o que ganha destaque nessa aposta ética é o que, no invisível, sustenta o encontro e a atmosfera crucial dos processos de ensino-aprendizagem: um pouco abertura e de frescor. 


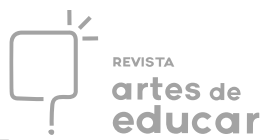

O manuseio da atenção na processualidade do pensamento: relações entre "atender" e "escutar"

No contexto da educação e da clínica ocidentais modernas, muito já se discutiu sobre a intimidade de relação entre o escutar e o atender, entre o ouvir e o atentar-se. Em nossas experiências formativas, podemos notar que um bom professor é aquele que incita, instiga e produz simpatia com o tema que trabalha, com rigor e leveza, sem pressionar nem precipitar um conteúdo, como se pudesse escutar a linha não verbal que move o pensamento e nos atrair para ela.

Deleuze (1987) afirma que para os estudantes também é crucial manter uma postura que aguarda e escuta, isto é, que não se antecipa em categorizar, tampouco conceitualizar a matéria movente de pensamento oferecida pelo professor. Assim, é aconselhável habitar tais linhas como se ouvíssemos uma composição musical e, desse modo, entrar na sinfonia, deixar-se envolver pela música do pensamento, sintonizando a atenção com o comprimento de onda das ideias. Dessa maneira, se o estudante puder escutar a processualidade do pensamento, ou seja, se puder acolher sua diferença, alguns dias depois de uma aula, pode ser que compreenda aquilo que em momento anterior lhe parecia estranho, confuso e sem nitidez.

Um clínico experiente, por seu turno, também porta-se como um caçador à espreita, quer dizer, pode manter-se imóvel durante praticamente toda a sessão e até mesmo no decurso de vários encontros clínicos, até que, no momento propício, nos interroga em razão dos vacilos e hesitações que deixamos à mostra - se não pelas palavras, pela ponta de nossos dedos (FREUD, 1912). Não acontece de modo diferente com um pesquisador que pretenda cartografar ${ }^{2}$ uma realidade, acompanhando as linhas entrelaçadas e bifurcantes da constituição de um domínio, quer seja conceitual, quer se trate de uma pesquisa que inclui a experiência de campo.

Poderíamos dizer que suscitar um terceiro ouvido e tocar as texturas de um terreno arenoso de investigação se oferece como possibilidade quando rastreamos, tocamos, fazemos um pouso e exercitamos o reconhecimento atento diante dos estranhamentos que se abrem em qualquer campo de pesquisa e investigação (KASTRUP, 2007, p.18), e a partir desta sintonia de composição criamos realidade em vez de simplesmente mapeá-la. Essa experiência ganha viço quando o pesquisador se dispõe a percorrer uma estrada sinuosa e empoeirada, em vez de se proteger e orientar apenas pelas direções do GPS em seu bolso. 
O psicanalista Alfredo Naffah Netto (1993) evoca a noção de "terceiro ouvido" como um modo de abordar a ultrapassagem do uso representativo e automatizado dos sons que conformam as palavras em favor de uma compreensão da escuta como "canal para a pulsação".

\begin{abstract}
Quem ousaria decifrar um discurso como se decifra uma partitura musical? E aguçar o terceiro ouvido - que é o que apreende o incorpóreo do texto? Tarefa penosa, árdua, dado que o nosso hábito é tecido nas malhas da linguagem representativa. Às vezes, no meio de uma sessão, quando me percebo seduzido pela tentação desse hábito, suspendo todo o conteúdo da fala do paciente e permaneço longos minutos escutando apenas a música do discurso: sua melodia, seu ritmo, seu timbre e todas as mudanças e flutuações que se seguem. Geralmente, quando volto às palavras tenho um novo ângulo de visão, deixei-me afetar de uma outra forma, e posso - através da minha fala criar passagem para um novo sentido, uma nova interpretação. Caberia chamar, aí, esse sutil canal, vibrátil e respons'hábil, de segunda garganta! (p. $155)$.
\end{abstract}

Talvez nem seja adequado falar em "o” bom professor, “o” bom clínico, estudante ou pesquisador, pois não é possível uma identidade que se erga de modo infalível e previsível em todas as ocasiões. Há muitas forças em jogo, e somente na relação direta, contextual e situada poderemos dizer que um gesto clínico, educativo ou pesquisador se instaurou. Tal gesto, inclusive, se nutre ao conjurar a dimensão profissional que certamente protege uma identidade, mas é no desvio e escape que a dimensão de potência escutadeira progride.

Como já dizia o título de um livro de poemas de Paulo Leminski (1987), Distraídos venceremos. Paradoxalmente, no entanto, é no instante em que "descemos" da árvore que "pretende" (vencer, educar, pesquisar, clinicar), no momento "im"preciso em que nos soltamos de suas raízes, que uma fruta madura despenca em nossa testa - como a maçã que caiu sobre a cabeça de Newton.

Muitos cientistas, filósofos e artistas mencionam essa qualidade escutadeira de abertura da atenção na emergência de uma ideia criadora, algo que se passa justamente ao nos disponibilizarmos quando escutamos uma ideia com o corpo inteiro. Claire Petitmengin (2007) investiga tal processo e afirma que uma nova ideia - antes de tomar sua forma precisa e transmissível - se apresenta como um fio condutor, ou seja, nos atravessa como um pressentimento, uma direção, uma linha de força que orienta nosso pensamento silenciosamente.

Quando nos dispomos a escrever um texto, literário ou não, podemos sentir essa linha de força inscrever em nós sua operação. É como se, por meio de um bisturi, a escrita movesse a ponta de nossos dedos e penetrasse a realidade textual na direção que lhe é própria.

Revista Interinstitucional Artes de Educar. Rio de Janeiro, V. 5, N.3- pág. 439-453 set-dez de 2019: “Educação: Corpo em movimento." - DOI: 10.12957/riae.2019.45776 


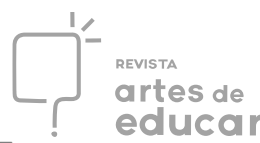

Recordamo-nos de que anos atrás, em uma aula de psicolinguística no curso de graduação em psicologia, o professor regente da matéria nos contou uma anedota que surge embaçada na memória e por isso não podemos explorar seus contornos precisos, mas ainda assim empenharemos palavra para fazê-lo. Tal anedota diz respeito a um conto, supostamente de Machado de Assis, que após ter sido dado como finalizado pelo escritor, foi enviado para a gráfica. Passados alguns dias, no entanto, os editores lhe remeteram o trabalho de volta dizendo que só poderiam publicá-lo caso o escritor lhe somasse mais umas tantas páginas ao final do conto. E então, sem alternativa aparente, o autor (que não podemos precisar quem foi) assim o fez, cumpriu o mandado social e apresentou uma nova versão estendida do trabalho. Mas o emblemático do acontecimento é que após a edição ter sido lançada e os críticos e leitores entrarem em contato com a obra, multiplicaram-se burburinhos alegando a percepção nítida de que as páginas ao final do conto haviam sido somadas como um "rabo" completamente desnecessário ao movimento e processualidade inerente ao texto.

Essa anedota parece indicar que a linha de força e de criação tem movimentos rebeldes e nos empurra em determinadas direções - e, assim, cabe a nós praticar uma modalidade de receptividade atencional para acolhê-la e gestá-la no tempo propício que lhe diz respeito, em vez de restringi-la a compromissos profissionais ou intencionais de um "eu". Como nos diz Carlos Drummond de Andrade (1976): "São tão fortes as coisas! Mas eu não sou as coisas e me revolto. Tem palavras em mim buscando canal [...] Apenas querem explodir” (p. 152).

Praticar essa abertura sutil às palavras empenhadas na busca de um canal de pulsação é habitar uma linha de força invisível, o que exige de nós o cultivo de uma postura concomitantemente atenciosa e escutadeira; exige, afinal, que escutemos com o corpo inteiro. É certo que nem sempre estamos disponíveis para recepcionar a ocorrência dos acontecimentos desse modo e frequentemente nos revoltamos contra o instante. ${ }^{3}$ Quer dizer, frequentemente temos dificuldade em deixar que as ideias ganhem movimento a seu turno, no tempo que lhe é próprio.

Petitmengin (2007) afirma que podemos adotar duas posturas distintas nessas ocasiões. A primeira consiste em procurar imediatamente classificar a ideia nascente em uma categoria conhecida, interpretá-la ou colocá-la de modo instantâneo em palavras - todas as quais têm o efeito de interromper sua evolução e congelá-la. A segunda postura, por sua vez, consiste em permanecer em contato com o sentido difuso e indescritível que é o seu germe e permitir que se torne mais precisa, por si só, sem forçá-la, dando espaço para que o tempo faça seu trabalho, pacientemente deixando-a amadurecer como no desabrochar delicado de uma flor. 
É curioso que entre estudantes pós-graduandos compareça como tema de conversas, frequentemente, a diferença nos modos de lidar com a escrita durante os períodos do mestrado e do doutorado. A sensação é frequentemente compartilhada: no período de mestrado, o processo todo é mais “doído, esforçoso, lutado", ao passo que durante os anos do doutorado a escrita tende a "fluir melhor". Em geral, num primeiro momento atribui-se essa diferença ao tempo disponível para empreender a atividade (dois anos no primeiro caso e quatro anos no segundo).

Se olharmos com cuidado, no entanto, podemos dimensionar que tal diferença talvez tenha menos a ver com a objetividade de um tempo cronológico e mais com o fato de que, nesse segundo momento, estamos mais familiarizados com o processo de operar da escrita. Quer dizer que adotamos com mais facilidade o segundo gesto de que fala Petitmengin (2007) e, assim, guardamos menos expectativas, nos assustamos menos com o funcionamento imprevisível da palavra, acolhemos os tempos de fagulhas e pingos d'água e os dias de letras torrenciais, além de lidarmos melhor com a demora da palavra em nascer.

Essa também é uma imagem recorrente: a escrita como um "parto". E assim como na gestação é necessário esperar o momento propício de dilatação adequada para que a parturiente possa dar à luz, também na escrita necessitamos dilatar a atenção e escutar com o corpo inteiro os afetos que pedem passagem. Assim, a indicação é mantermo-nos empenhados e aguardarmos. E quando um centímetro cúbico de oportunidade se interpõe e abre uma brecha, então nós agimos ligeiros, ainda que recuados desde uma posição de atenção à espreita.

Quando estamos escrevendo um texto, é comum também invocarmos outra imagem: que a "entidade" (escrita) baixe sobre nós! Recordamo-nos de uma conversa, anos atrás, com uma estudante amiga que frequentava uma religião de matriz africana (Umbanda) e de maneira bastante devota "recebia santos". Na ocasião, perguntamos a ela de modo interessado e curioso como a mediunidade acontecia. Queríamos saber se ela se mantinha consciente ou não, se lembrava após as sessões do que havia ocorrido no seu transcurso etc. A sua resposta foi muito interessante. Disse que sim, permanecia consciente. Porém, era como se estivesse "recuada" diante das entidades, que ganhavam a dianteira das palavras e gestos que ela proferia. Não é à toa que, nessa tradição, quem recebe santo é chamado de "cavalo". E esta nos parece também uma boa imagem para dimensionar a relação de abertura com a criação e a escrita, pois desde que tenhamos nos disposto a esse gesto sensível, então a palavra parecerá mesmo praticar um tipo de "montaria" sobre nossos ombros. 
Vale dizer que o acolhimento dos afetos impessoais enganchados à conversão atencional e à potência escutadeira nos processos de criação ultrapassa o procedimento da escrita, isto é, ultrapassa o empenho da palavra em fazer nascer textos.

No livro $O$ ator invisível, do dramaturgo japonês Yoshi Oida (2001), lemos que um bom ator não é aquele que brilha e enche nossos olhos com suas habilidades, beleza ou qualquer outro tipo de atributo. Pelo contrário, um bom ator é justamente aquele que se mantém recuado para escutar e acolher com o corpo inteiro a personagem e assim desaparece para que a cena possa se destacar às nossas vistas. Quer dizer, é a personagem que dá o tom, gradiente e ritmo para o trabalho, por isso mesmo o ator precisa abandonar os trejeitos e figurinos habituais de um eu.

Nessa mesma direção, Bergson (1999) também afirmava que aprender a ler, ${ }^{4}$ assim como escutar com o corpo inteiro - como gesto ético de postura escutadeira -, tem pouco parentesco com a atividade categorial e linear de sistematização de letras e palavras; ao contrário, mais se aproxima do jogo processual e movente de adivinhação e criação a que nos referimos.

Em todas essas situações e contextos, uma potência escutadeira depende de aprendermos a manusear a atenção com objetos moventes, isto é, de estarmos mergulhados em meio ao acompanhamento de ideias, pensamentos e sentidos para os acontecimentos, sem que ocorra necessariamente um processo de focalização disciplinada. A essa altura, poderíamos até mesmo perguntar: quais são, afinal, as diferenças entre "atender" e "escutar"?

Não parece à toa, pois, que o exercício clínico (um trabalho por excelência de escuta de sinais e possibilidades de desvios existenciais) seja cotidianamente chamado de "atendimento" nos consultórios de psicólogos, fisioterapeutas, médicos ou nutricionistas. Talvez até mesmo a palavra "auscultação" fosse mais adequada, pois quando um médico ausculta nossos batimentos cardíacos, por exemplo, utiliza ao mesmo tempo o ouvido e o toque em nossa pele, e a tecnologia relacional da "postura escutadeira" a que nos referimos é também altamente sensitiva e tátil.

Claire Petitmengin (2007) também aponta uma dimensão sutil de desfazimento das fronteiras e de permeabilidade entre os planos interior versus exterior, relacionando essa abertura a uma qualidade de sintonia rítmica instaurada nas relações clínicas e de aprendizagem. Tal experiência é sem dúvida experimentada na sala de aula, em espaços de criação artística e outros processos formativos, no teatro e no cinema, quando espectador e obra parecem se diluir como entidades independentes, marcando-se o caráter coemergente que Revista Interinstitucional Artes de Educar. Rio de Janeiro, V. 5, N.3- pág. 439-453 set-dez de 2019: "Educação: Corpo em movimento." - DOI: 10.12957/riae.2019.45776 


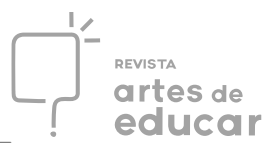

caracteriza um encontro singular. Na sala de aula, também é possível experimentarmos o desmanche das hierarquias e fronteiras disciplinares quando nos sentimos mergulhados no universo de sentido e de pensamento que ao mesmo tempo nos atrai, desassossega, nos move e nos distancia de nós mesmos.

\section{Considerações finais}

A pertinência desse debate parece se inscrever diante do fato de que em meio à aceleração que desafia o cotidiano das escolas, contemporaneamente, não se faz muita propaganda dessas linhas "escutadeiras", delicadas e sutis, da potência de escuta com o corpo inteiro, muito menos das camadas menos visíveis da atenção. Ainda hoje, o ato de focalizar mais alinhado ao produtivismo e tarefismo demandados pelo modo de produção capitalista costuma ser sonhado por muitos educadores e ser entendido como a verdadeira prática de atenção que se almeja alcançar.

As palavras de ordem - "Preste atenção para aprender, menino!" - tão corriqueiramente bradadas por nós, educadores, desconsideram e ocultam o fato de que atender de modo atencioso também requer um processo de aprendizagem consistente e trabalhoso (KASTRUP, 2004). O aprendizado da sensibilidade que está em jogo no aprender a atender não se efetiva individualmente, nem de modo espontâneo, tampouco é tarefa a ser cumprida apenas pelos estudantes. É um desafio coletivo a ser sustentado e praticado por uma comunidade escolar sem muros: somos todos convidados para a "festa"!

Esses convites, no entanto, são amplamente distribuídos em várias direções, mas recusados em considerável proporção. Vivemos em tempos de globalização generalizada, de volatilidade e alto índice de dispersão, tempos de tecnologias digitais cada vez mais modernas lançadas a cada ano, de descartabilidade de objetos e relações e, enfim, tempos de internet disponível e acessível para todos, sobretudo jovens. Mesmo nas regiões rurais ou comunidades e periferias alijadas de recursos e direitos básicos, é comum que os alunos possuam acesso à internet em seu cotidiano. E, se por um lado a internet abre janelas e permite que viagens de conhecimento inimagináveis nos alcancem, por outro lado, dependendo do modo como estabelecemos relação com esta magnífica ferramenta, pode ser também um fator de 


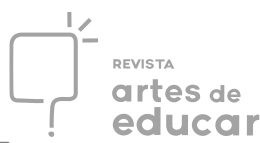

agravamento da dispersão e volatilidade em nossos dias, tornando o conhecer raso e superficial, como um clique que encerra a potência de diferenciação ao invés de abri-la.

O uso de celulares com internet entre estudantes do ensino médio em escolas públicas e privadas, mas também em faculdades e universidades, é questão que não se resolve. Não é à toa que Yves Citton (2017) irá chamar esse instrumento aparentemente inofensivo de vampiro atencional. Tal denominação surge diante da eficácia deste aparelho para sugar nossa atenção e capturar a energia de nossas baterias corporais. Uns professores mais rígidos proíbem o uso de celulares nas salas de aula, outros apostam na responsabilidade e autonomia dos estudantes e, francamente, a maioria de nós sapateia e recoloca o tema frequentemente em pauta ao longo do ano letivo, adotando ora posturas mais enérgicas, ora mais permissivas. Aliás, não podemos deixar de mencionar que muitas vezes são os próprios estudantes que necessitam reposicionar os vícios tecnológicos que afligem também a nós, os professores.

O regime de atenção em voga no contemporâneo configura uma experiência em que quase não pousamos em nada, isto é, os acontecimentos passam muito rápido e não reverberam, pois o que está em foco é rapidamente atropelado pelo próximo tema, o novo assunto, a moda do momento, a tarefa seguinte. Deste modo, enfrentamos dificuldades para coordenar a tríade corpo/atenção/ação e, de maneira desalinhada, investimos uma cognição abstrata e descorporificada. Nesta configuração de existência os dias voam, passam quase despercebidos...

Vale mencionar que nas escolas também é comum entre nós, professores, queixas diante da dificuldade para concluir um conteúdo programático de aula. Também é um desafio dar conta dos temas que precisam ser abordados ao longo de um semestre ou ano letivo. Em parte essa dificuldade pode ser atribuída à política recognitiva que assola professores e estudantes com excesso de conteúdos. No entanto, não podemos desconsiderar que a dificuldade reside também na dificuldade de manejar os "assaltos" atencionais que acometem a experiência compartilhada, dando-nos a sensação de que o tempo é sempre pouco para a quantidade de tarefas, pois a mudança ininterrupta de foco desafia a espessura e a consistência das experiências.

Vivemos nestes tempos desafiadores, diga-se de passagem, em que os vacúolos solidários de silêncio, atenção e cuidado nas escolas têm sido cada vez mais engolidos por múltiplas exigências e controles: preenchimentos burocráticos de inúmeras papeladas, correrias entre uma sala e outra, precariedade das condições de trabalho, excesso de exames que amedrontam os estudantes ao invés de convocá-los ao pensamento, conteúdos e metas a cumprir Revista Interinstitucional Artes de Educar. Rio de Janeiro, V. 5, N.3- pág. 439-453 set-dez de 2019: "Educação: Corpo em movimento." - DOI: 10.12957/riae.2019.45776 


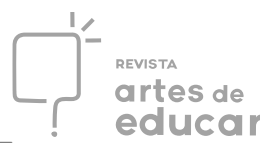

construídos de modo hierárquico, relações fragilizadas com a comunidade e as com famílias, turmas superlotadas, enfim, um excesso de ocupação que desafia a raridade da companhia, da postura lateralizada, do compartilhamento genuíno e dos espaços de conversa franca entre as pessoas.

Os arrochos salariais, o descaso, a escassez de tempo, de recursos e a restrição de direitos trabalhistas são o espelho de um governo que não aposta na potência transformadora da educação, tampouco alimentará espaços democráticos de produção de saúde, vacúolos de silêncio, escuta franca e partilha da palavra. No caso mais específico do ambiente educacional os espaços de diálogo são cada vez mais restritos e apressados' resumindo-se ao fornecimento de diretrizes que devem ser seguidas e/ou obedecidas - não só pelos estudantes, mas, sobretudo, pelos próprios trabalhadores da educação que frequentemente verbalizam a sensação de serem massacrados pelo sistema e sentirem-se exaustos. Imersos em condições adversas como o cenário duro que se apresenta resta aos trabalhadores a minúcia da aposta, a luta coletiva ancorada em vínculos solidários, a engenhosidade e a astúcia de fazer surgir uma manhã e sustentá-la, "apesar de".

Afinal, apesar dos poderes que pretendem nos amordaçar nós teimamos em resistir, confeccionamos redes como aranhas tecem suas teias em paredes contíguas. Os processos de ensino-aprendizagem que permeiam o cotidiano das escolas não se resumem, pois, às normas e organizações fechadas, tampouco aos planejamentos verticalizados e à rotina dos dias. $\mathrm{O}$ cotidiano é marcado por acontecimentos imprevisíveis e singulares, o que exige de nós disponibilidade para percebê-los através da habitação de linhas prenhes de invenção. Como afirma Michel de Certeau (1994) o cotidiano se inventa com mil maneiras de caça não autorizada (p. 38). Deste modo, há indícios de um campo de forças sempre em disputa e resistências que se atualizam em táticas inesperadas.

Podemos dizer que estas táticas se reverberam quando escutamos com o corpo inteiro, através da partilha da palavra que faz ruir nossas teses e pressupostos. Nesse movimento, ancoramos a possibilidade de uma existência aberta ao que advém em percursos situados e contextuais, permitindo-nos a dissolução dos pontos de vista quando estes já não tem mais viço, não compõem com a festa e nem com a ocasião. Certamente, tal exercício não se faz de modo espontâneo e sem a montagem de táticas ancoradas em dispositivos e espaços de produção coletiva.

Em outras palavras, podemos dizer que os exercícios de escuta com o corpo inteiro e de atenção à processualidade e às sutilezas exigem o cultivo de uma postura concomitantemente Revista Interinstitucional Artes de Educar. Rio de Janeiro, V. 5, N.3- pág. 439-453 set-dez de 2019: "Educação: Corpo em movimento." - DOI: 10.12957/riae.2019.45776 


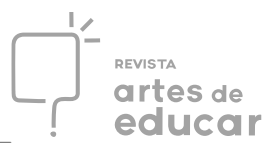

aberta e disponível ao que costuma ser pormenorizado e desvalorizado em nossa sociedade. A musicista Evelyn Glennie (2015) nos fornece boas pistas para pensar o corpo em sua função ampliada como "caixa de ressonâncias" e parece indicar caminhos para um exercício de práticas de desnaturalização do que se apresenta como modelo de educação informacional.

A percussionista nos convida a praticar a escuta como possibilidade de habitação da linha de força invisível que compõe nossa dimensão sempre coemergente e relacional, além de nos convidar a escutar com os braços, pernas, com a nuca, o peito, as costas e a planta de nossos pés. Trata-se de ancorar a experiência em sua dimensão corporal e de coordenar a tríade atenção/escuta/corpo. O trabalho de Evelyn Glennie é um convite para uma aprendizagem da sensibilidade, da atenção e da escuta e sem dúvida nos ajuda a construir pistas para nossa atuação como educadores em sala de aula. ${ }^{5}$

\section{REFERÊNCIAS}

ANDRADE, Oswald de. O manifesto antropófago. In: TELES, G. M. Vanguarda europeia e modernismo brasileiro: apresentação e crítica dos principais manifestos vanguardistas. 3. ed. Petrópolis: Vozes; Brasília: INL, 1976.

BARROS, R. D. B.; PASSOS, E. A cartografia como método de pesquisa-intervenção. In: PASSOS, E.; KASTRUP, V.; ESCÓSSIA, L. (orgs.). Pistas do método de cartografia: pesquisa-intervenção e produção de subjetividade. Porto Alegre: Sulina, 2009.

BERGSON, Henri. Matéria e memória. São Paulo: Martins Fontes, 1999.

CERTEAU, Michel de. A invenção do cotidiano: Artes de fazer. Petrópolis: Vozes, 1994.

CITTON, Yves. The ecology of attention. UK: Polity, 2017.

DELEUZE, Gilles. Proust e os signos. Rio de Janeiro: Forense Universitária, 1987.

DELEUZE, G.; PARNET, C. Diálogos. São Paulo: Escuta, 1998.

FREUD, Sigmund. Recomendações aos médicos que exercem a psicanálise. In: FREUD, S. Obras psicológicas completas de Sigmund Freud: edição standard brasileira. v. XII. Rio de Janeiro: Imago, 2006 [1912].

GLENNIE, E. Hearing essay: Evelyn Glennie teach the world to listen, 2015. Disponível em: https://www.evelyn.co.uk/hearing-essay/?fbclid=IwAR0vSOz-

9ccaY3Lrhv7QG2L2niDtCDKqOcSfddG9gLVGVDDvrnYLuqPaK_o. Acesso em: 22 out. 2018. 


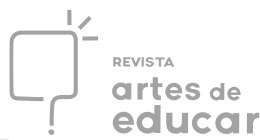

KASTRUP, Virgínia. A aprendizagem da atenção na cognição inventiva. Psicologia \& Sociedade, Belo Horizonte, v. 16, n. 3, p. 7-16, 2004.

O funcionamento da atenção no trabalho do cartógrafo. Psicologia \& Sociedade, Belo Horizonte, v. 19, n. 1, p. 15-22, 2007.

LEMINSKI, Paulo. Distraídos venceremos. São Paulo: Brasiliense, 1987.

LISPECTOR, Clarice. Água viva. Rio de Janeiro: Nova Fronteira, 1996.

NETO, Alfredo. O terceiro ouvido: Nietzsche e o enigma da linguagem. Cadernos de Subjetividade: Núcleo de Estudos da Subjetividade, PPG Psicologia Clínica/ PUC-SP, São Paulo, v. 1, n. 2, p.151-155, 1993.

HANH, Thich Nhat. O sol meu coração: da atenção à contemplação intuitiva. São Paulo: Paulus, 1996.

OIDA, Yoshi. O ator invisível. São Paulo: Beca Produções Culturais, 2001.

PETITMENGIN, Claire.. Towards the source of thoughts. Journal of Consciousness Studies, v. 14, n. 3, p. 54-82, 2007.

TOUCH THE SOUND. Documentário. Direção de Thomas Riedelsheimer. Alemanha. 2004. 1 DVD (100 min.). Disponível em: https://www.youtube.com/watch?v=Px8JC5DfoWs. Acesso em: 20 set. 2019.

\footnotetext{
' Professora substituta do departamento de Psicologia da Universidade Federal do Espírito Santo (UFES). Doutoranda em Educação pela UFES, mestre em Psicologia pela Universidade Federal Fluminense (UFF), graduada em Psicologia pela UFES. Vitória, ES, Brasil. E-mail: crisbremenk@gmail.com. ORCID: https://orcid.org/0000-0003-0854-7687.

ii Professora titular do departamento de Psicologia da Universidade Federal do Espírito Santo (UFES), do Programa de Pós-Graduação em Educação e do programa de Psicologia Institucional da UFES. Vitória, ES, Brasil. E-mail: betebarros@uol.com.br Orcid: https://orcid.org/0000-0003-1123-4374.

${ }^{3} \mathrm{O}$ desenvolvimento dessa ideia pode ser acompanhado na transcrição de um ensinamento do professor budista Lama Padma Samten, disponível no seguinte endereço eletrônico: <http://www.cebb.org.br/as-cinco-sabedoriasna-educacao-e-o-treinamento-do-cebb/>. Acesso em: 05 set. 2019.

${ }^{4}$ A cartografia como método de pesquisa-intervenção visa acompanhar processos de produção de subjetividade e pressupõe uma orientação do trabalho do pesquisador que não se faz de modo prescritivo, por regras já prontas, nem com objetivos previamente estabelecidos. No entanto, não se trata de uma ação sem direção, pois é pautada por um princípio ético de considerar os efeitos do processo do pesquisar sobre o objeto da pesquisa, o pesquisador e seus resultados (BARROS; PASSOS, 2009).

5 "Nada existe de mais difícil do que entregar-se ao instante. Esta dificuldade é dor humana. É nossa." (LISPECTOR, 1996, p. 49).

${ }^{6}$ Nas palavras do autor: “Contra Grashey, que havia sustentado num estudo célebre que lemos as palavras letra por letra, esses pesquisadores estabeleceram que a leitura corrente é um verdadeiro trabalho de adivinhação, nosso espírito colhendo aqui e ali alguns traços característicos e preenchendo todo intervalo com lembrançasimagens que, projetadas sobre o papel, substituem-se aos caracteres realmente impressos e nos dão sua ilusão. Assim, criamos ou reconstruímos a todo instante. Nossa percepção distinta é verdadeiramente comparável a um círculo fechado, onde a imagem-percepção dirigida ao espírito e a imagem-lembrança lançada no espaço correriam uma atrás da outra" (BERGSON, 1999, p. 117).
} 
Revista Interinstitucional Artes de Educar. Rio de Janeiro, V. 5, N.3- pág. 439-453 set-dez de 2019: "Educação: Corpo em movimento." - DOI: 10.12957/riae.2019.45776 